\title{
COVID-19-related Abdominal Aortic Thrombosis
}

\author{
Cengiz Güven ${ }^{1}$
}

\begin{abstract}
Thrombotic complications increase in novel coronavirus disease 2019 (COVID-19) patients. Most of these complications are associated with venous thromboembolism and pulmonary embolism; and arterial thrombosis is rare. Usually, arterial thrombosis affects peripheral arteries. The involvement of large vessels, such as aorta, is rare in the literature. Major artery thrombosis manifests with different additional complications. Contrast-enhanced abdominal computed tomography angiography (CTA) was performed on a patient, who was followed-up with COVID-19 due to gastrointestinal symptoms. Supra-celiac aortic thrombosis and splenic infarction were detected. This case is reported to share experience regarding our treatment approach in the light of the literature data.
\end{abstract}

Key Words: Arterial thrombosis, Acute aortic thrombosis, COVID-19.

How to cite this article: Güven C. COVID-19-related Abdominal Aortic Thrombosis. J Coll Physicians Surg Pak 2021; 31(JCPSPCR):CR130-CR131.

\section{INTRODUCTION}

Acute aortic thrombosis is a rare disease with serious complications. Mostly, clinical symptoms manifest aggressively with embolism and related complications in lower extremities and with complications, such as symptoms because of gastrointestinal malperfusion as a result of spinal ischemia, renal infarction, and stroke. ${ }^{1}$ The most important organ of involvement in COVID-19 is the lung. ${ }^{2}$ However, the most important cause of poor prognosis is coagulopathy. ${ }^{1}$ Various venous and pulmonary embolisms were detected in the literature review. ${ }^{3}$ In this case, supra-celiac partial aortic thrombosis was detected on computed tomography angiography (CTA) carried out for abdominal pain two weeks after COVID-19 diagnosis. The patient agreed to release all laboratory data and images.

\section{CASE REPORT}

A 54-year male patient, who had no previous respiratory complaints, wasadmitted totheEmergency Department with shortness of breath and cough. Asidefrom excessive smoking and uncontrolled diabetes, his medical history was not significant. No significant pathology was detected on chest $\mathrm{x}$-ray. Laboratory tests revealed D-Dimers of $9650 \mu \mathrm{g} / \mathrm{L}, \mathrm{C}$-reactive protein (CRP), 23.8 $\mathrm{mg} / \mathrm{dL}$, fibrinogen, $738.3 \mathrm{mg} / \mathrm{dL}$, interleukin-6, $938 \mathrm{pg} / \mathrm{mL}$ and ferritin of $1500 \mathrm{ng} / \mathrm{ml}$. Thoracic CT was then carried out, and density changes along with patchy-consolidated ground glass opacities were detected in bilateral pulmonary parenchyma with subpleural-parenchymallocalisation (Figure 1).

Correspondence to: Dr. Cengiz Güven, Department of Cardiovascular Surgery, Adiyaman University School of Medicine, Adlyaman, Turkey

E-mail: guvencengz@yahoo.com

Received: November 18, 2020; Revised: February 24, 2021; Accepted: April 25, 2021

DOI: https://doi.org/10.29271/jcpsp.2021.JCPSPCR.CR130

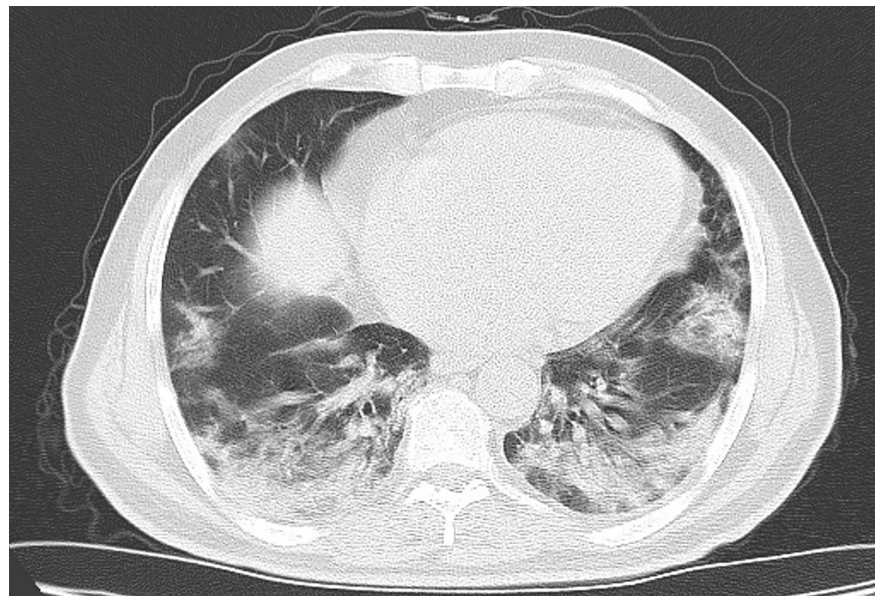

Figure 1: Chest CT scan showing characteristic findings of COVID-19 infection.

The PCR was positive for COVID-19. The patient was hospitalised, and given standard COVID-19 treatment. Abdominal contrast-enhanced CTA was carried out for mild nausea and abdominal pain in the second week of this treatment, and findings confirmed the splenic parenchymal infarction detected on abdominal ultrasonography. A filling defect caused by partial thrombus in 2-cm segment of abdominal aorta at supra-celiac level and splenic parenchymal infarction were detected (Figure $2 \mathrm{~A}, \mathrm{~B})$. Medical treatment was decided and enoxaparin was started at $8000 \mathrm{IU} / 12$ hour. The thrombus completely disappeared without any additional complications in the abdominal CT carried out one month later (Figure 2C).

\section{DISCUSSION}

COVID-19 is a viral disease, which was declared as a pandemic by the World Health Organization in March 2020, and has affected millions of people. ${ }^{4}$ Although this infection mostly affects the respiratory system, it also causes various cardiovas- 
cular effects. Specially, patients who have previous cardiovascular disease are at higher risk for these effects. ${ }^{5}$ Disease severity, inflammatory response, and hypoxia predispose the affected patients to thrombotic events. The initial data in the literature showed that many hemostatic abnormalities occur in patients who are affected by COVID-19, which include intravascular coagulation. ${ }^{3,6}$

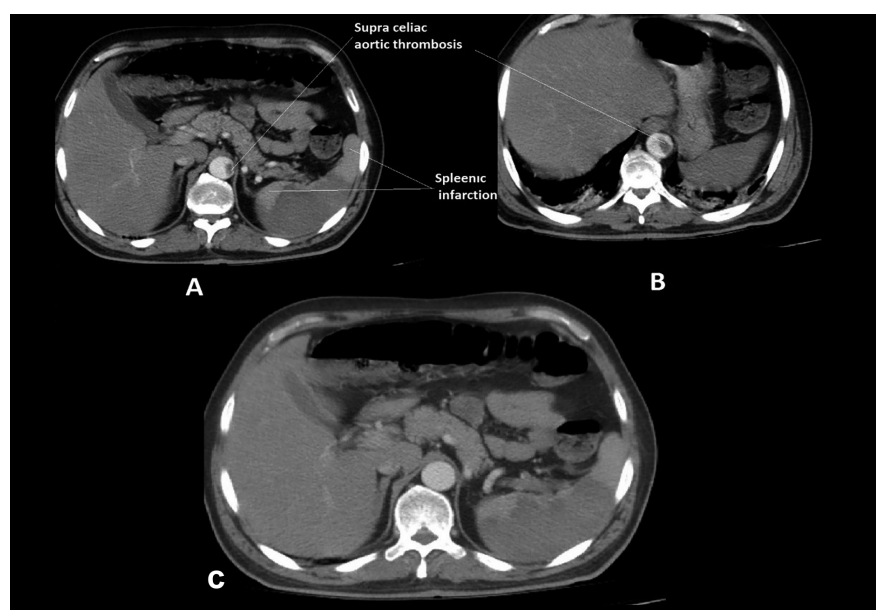

Figure 2: Contrast-enhanced CT scan of abdomen showing partial thrombosis of abdominalaorta and splenicinfarction.

Many of the increased thromboembolic events in COVID-19 are related to venous thromboembolism and pulmonary embolism. However, recent publications and case reports show increased frequency of arterial thrombosis. ${ }^{7}$

Although the exact cause of thromboembolic events in COVID-19 is not elucidated completely, some factors are implicated in this respect. The invasion of the virus into vascular endothelial cells can initiate this event with a significant increase in cytokines (especially interleukin-6) and acute phase reactants. ${ }^{3}$ Another factor is that drugs used in COVID-19 treatment might cause unwanted drug interactions in patients who use antiplatelet anticoagulants. ${ }^{4}$

This patient had no systemic disease aside from uncontrolled diabetes. However, he was a heavy smoker, and his infection was severe. Vascular diabetic complications, cytokine storm, and endothelial dysfunction by the virus might have most probably caused the aortic thrombosis in this case, ${ }^{8}$ who developed this event under prophylactic dose of low molecular-weight heparin. Full-dose (therapeutic dose) anticoagulation was initiated after aortic thrombosis diagnosis. One month later, the follow-up CT showed complete dissolution of the thrombus.

In conclusion, this case highlights the need to keep in mind the possibility of arterial thrombosis in case patients with COVID-19 develop new symptoms unrelated to COVID-19 infection.

\section{CONFLICT OF INTEREST:}

The author declared no conflict of interest.

\section{PATIENT'SCONSENT:}

Written consent was taken from the patient to publish the data related to the case.

\section{AUTHOR'S CONTRIBUTION:}

CG: Analysis, interpretation of data, writing report, diagnosis and treatment.

\section{REFERENCES}

1. Baeza C, González A, Torres P, Pizzamiglio M, Arribas A, Aparicio C. Acute aortic thrombosis in COVID-19. J VasC Surg Cases Innov Tech 2020; 6(3):483-6. doi: 10.1016/ j.jvscit.2020.06.013.

2. Pascarella G, Strumia A, Piliego C, Bruno F, Del Buono R, Costa $F$, et al. COVID-19 diagnosis and management: $A$ comprehensive review. J Intern Med 2020; 288(2):192-206. doi: 10.1111/joim.13091.

3. Tang N, Bai H, Chen X, Gong J, Li D, Sun Z. Anticoagulant treatment is associated with decreased mortality in severe coronavirus disease 2019 patients with coagulopathy. J Thromb Haemost 2020; 18(5):1094-9. doi: 10.1111/ jth.14817.

4. Bikdeli B, Madhavan MV, Jimenez D, Chuich T, Dreyfus I, Driggin E, et al. COVID-19 and thrombotic or thromboembolic disease: Implications for prevention, antithrombotic therapy, and Follow-Up: JACC state-of-theart review. J Am Coll Cardiol 2020; 75(23):2950-73. doi: 10.1016/j.jacc.2020.04.031.

5. Driggin E, Madhavan MV, Bikdeli B, Chuich T, Laracy J, Biondi-Zoccai G, et. al. Cardiovascular considerations for patients, health care workers, and health systems during the COVID-19 pandemic. J Am Coll Cardiol 2020; 75(18):2352-71. doi: 10.1016/j.jacc.2020.03.031.

6. Lew TW, Kwek TK, Tai D, Earnest A, Loo S, Singh K, et al. Acute respiratory distress syndrome in critically ill patients with severe acute respiratory syndrome. JAMA 2003; 290(3):374-80. doi: 10.1001/jama.290.3.374.

7. Gomez-Arbelaez D, Ibarra-Sanchez G, Garcia-Gutierrez A, Comanges-Yeboles A, Ansuategui-Vicente M, GonzalezFajardo JA. COVID-19-related aortic thrombosis: A report of four cases. Ann Vasc Surg 2020; 67:10-13. doi: 10.1016/ j.avsg.2020.05.031.

8. Hussain A, Bhowmik B, do Vale Moreira NC. COVID-19 and diabetes: Knowledge in progress. Diabetes Res Clin Pract 2020; 162:108142. doi: 10.1016/j.diabres.2020.108142. 